Canadian

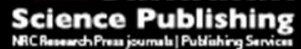

Canadian Journal of Physiology and Pharmacology Revue canadienne de physiologie et pharmacologie

\title{
The protective effect of trimetazidine against cisplatin- induced nephrotoxicity in rats
}

\begin{tabular}{|r|l|}
\hline Journal: & Canadian Journal of Physiology and Pharmacology \\
\hline Manuscript ID & cjpp-2015-0472.R1 \\
\hline Manuscript Type: & Article \\
\hline Complete List of Authors: & $\begin{array}{l}\text { El-Sherbeeny, Nagla; Taibah University- Faculty of Pharmacy, } \\
\text { Pharmacology; Faculty of Medicine- Suez Canal university, Clinical } \\
\text { Pharmacology } \\
\text { Attia, Ghalia; Faculty of Medicine, Taibah University, Department of } \\
\text { Anatomy; Faculty of Medicine, Mansoura University, Department of } \\
\text { Histology \& Cell Biology }\end{array}$ \\
\hline Keyword: & Cisplatin, Oxidative stress, Trimetazidine, nephrotoxicity, NF-kB \\
\hline \multicolumn{2}{|c}{} \\
\hline
\end{tabular}

SCHOLARONE ${ }^{m}$

Manuscripts 
The protective effect of trimetazidine against cisplatin- induced nephrotoxicity in rats

Nagla A. El-Sherbeeny ${ }^{1} * \&$ Ghalia M. Attia ${ }^{2}$

1 Department of Pharmacology and Toxicology, College of Pharmacy, Taibah University, Al-Madinah Al-Munawarah, Saudi Arabia \& Department of clinical Pharmacology, Faculty of Medicine, Suez canal University, Egypt

2 Department of Anatomy, Faculty of Medicine, Taibah University, Al-Madinah AlMunawarah, Saudi Arabia \& Department of Histology \& Cell Biology, Faculty of Medicine, Mansoura University, Al Mansoura, Egypt.

*Correspondence

Dr. Nagla El-Sherbeeny, MD, PhD

n_elsherbeeny@hotmail.com

Mobile: 00966508218725

Permanent address: Department of clinical pharmacology, Faculty of Medicine, Suez Canal University, University road, Ismailia, Egypt. 


\begin{abstract}
Nephrotoxicity is a dose-limiting side effect of cisplatin (CSP). The study investigated the possible protective role of trimetazidine (TMZ) against CSP-induced nephrotoxicity in rats. Rats were divided into 4 groups; control Group, TMZ Group, CSP Group, and CSP + TMZ Group. CSP group showed significant deterioration in kidney function with structural changes in the form of interstitial hemorrhage glomeruli shrinkage and peritublar capillary congestion, tubular cells vacuolation, pyknosis, shedding and necrosis and inflammatory cell infiltrates; all indicating renal damage. CSP also caused a significant increase in the lipid peroxidation marker malondialdehyde levels (MDA), renal NF- $\kappa$ B (nuclear factor-kappa B) DNA-binding activity and protein expression, tumor necrosis factor- alpha (TNF- $\alpha$ ) and IL-6 levels. Treatment with TMZ before and after CSP injection produced significant improvement of kidney function and histopathology. TMZ treatment also significantly attenuated CSP-induced oxidative stress and suppressed elevated levels of TNF- $\alpha$ and IL-6, NFאB expression and its DNA-binding activity caused by CSP administration.TMZ has protective effect against CSP-induced nephrotoxicity mediated by reduction of oxidative stress, and attenuation of CSP- induced inflammation.
\end{abstract}

Keywords: Cisplatin, Oxidative stress, Trimetazidine, nephrotoxicity, NF-кB 


\section{Introduction}

TMZ, a piperazine derivative, is the first of a new class of metabolic agents. It has been found to have a cytoprotective effect on both renal and hepatic cells (Cristina et al. 2013). TMZ is well known for its cardioprotective effect and is used as adjuvant anti-anginal drug. It can normalize metabolic disturbances in low-flow myocardial ischemia and prevents the secondary cell death that may follow (Kantor et al. 2000; Sellier and Broustet 2003). TMZ acts by preserving intracellular levels of ATP through shifting cardiac metabolism from fatty acid oxidation to more glucose oxidation (Kantor et al. 2000). The drug may also reduce free-radical-mediated injury (Kaur et al. 2003), inhibit cell apoptosis (Khan et al. 2010) and improve endothelial function (Park et al. 2010).

Cis-Diammineplatinum (II) dichloride (CSP) is the prototype of the platinum containing anti-cancer drugs. It's widely used in clinical practice as part of the standard treatment plans for various solid tumors (Oh et al. 2014). CSP adverse effects include ototoxicity, bone marrow suppression and hepatotoxicity but the main doselimiting side effect of CSP is nephrotoxicity (Sastry and Kellie 2005). The most serious presentation of CSP-nephrotoxicity is acute kidney injury that can occur in 20$30 \%$ of patients treated with the drug (Miller et al. 2010).

The mechanisms of CSP-induced nephrotoxicity are complex and are mediated by numerous cellular processes including oxidative stress, apoptosis, and inflammation 
(Pabla and Dong 2008). Reactive oxygen species (ROS) are normally produced in the kidney while endogenous antioxidants such as glutathione peroxidase (GHx), superoxide dismutase (SOD), and catalase (CAT) act as scavengers of renal ROS (Kumari and Setty 2012).Various studies demonstrated the role of oxidative stress in CSP-induced nephrotoxicity. CSP increases ROS production by cellular xanthinexanthine oxidase system, mitochondria, and NADPH oxidase which are implicated in the pathogenesis of CSP-acute renal injury (Kawai et al. 2006). CSP can also decrease the activity of renal antioxidant enzymes, SOD, GHx, and CAT (Badary et al. 2005). CSP induces necrosis and apoptosis of renal tubular cells through activation of mitochondrial intrinsic and extrinsic pathways (Pabla and Dong 2008).

Following CSP administration, the expression of inflammatory cytokines by the kidney is increased. CSP causes activation of the transcription factor, NF- $\mathrm{BB}$ and proinflammatory pathways including TNF- $\alpha$ (Sahu et al. 2014).

Hypoxia and mitochondrial injury are involved in CSP nephrotoxicity. Pathological changes in CSP nephrotoxicity occur mainly in the S3 segment of the proximal tubule in the outer medulla. This zone of the kidney is more susceptible to ischemic insult, and injury to this segment occurs in other toxic acute renal failure models (Winston and Safirstein 1985).

Strategies for therapeutic intervention to minimize CSP-induced nephrotoxicity may include inhibition of pathways activating CSP to a nephrotoxin, use of antioxidants to 
scavenge the excessive production and attenuate the damaging effect of ROS, and inhibition of apoptotic mechanisms activated by CSP (Hanigan and Devarajan 2003). The current study was undertaken to investigate the possible protective role of TMZ against CSP-induced renal damage in rats and to elucidate the possible underlying mechanism.

\section{Materials and methods}

\section{Materials}

Cisplatin (Bristol-Myers- Squibb Co.) was obtained as the pharmaceutical drug (5 $\mathrm{mg} / \mathrm{mL}$ vial) and was diluted with isotonic saline. Trimetazidine dihydrochloride; (Vastarel MR) from (Servier, France). All of the remaining chemicals were of the highest commercially available grade.

\section{Animals}

Twenty four male Sprague Dawley rats weighing 150-200 g were used. They were obtained from the National Centre of Research (Cairo, Egypt). The animals were maintained under standard hygienic conditions in clean cages and a normal 12 light/dark cycle. They were allowed to acclimatize for 5 days before starting the experiment, fed a standard chow and allowed access to water ad libitum. The experimental protocol conducted in the study complies with the ethical guidelines and the principals of care, use and handling of experimental animals adopted by "The research Ethics Committee", Faculty of Medicine, Suez Canal University, Egypt 
which is in accordance with "Principles of Laboratory Animals Care" (NIH publication No. 85-23, revised 1985).

\section{Experimental protocol}

Twenty four rats were divided randomly into four groups with six rats for each group.

Group I: control group; received daily i.p. injections of normal saline solution (CSP vehicle) and $0.5 \mathrm{ml}$ of $0.5 \%$ carboxymethyl cellulose p.o. (TMZ vehicle). Group II: received TMZ (20 mg/kg/day, p.o.) for ten consecutive days, Group III: received drug vehicle daily for ten days with CSP given on the fifth day of the experiment (6 $\mathrm{mg} / \mathrm{kg}$, i.p., divided into 2 doses, 12 hrs apart), and Group IV: received TMZ for ten consecutive days $(20 \mathrm{mg} / \mathrm{kg} /$ day, p.o.) with CSP injected on the fifth day (6 mg/kg, i.p., divided into 2 doses, 12 hrs apart). This treatment schedule and dose level were chosen based on the results obtained from pilot experiments using lower doses of TMZ $(10,15 \mathrm{mg} / \mathrm{Kg} /$ day $)$ taking in consideration renal damage indexed as serum creatinine and blood urea nitrogen $(\mathrm{BUN})$, and mortality rate.

On day 4 after cisplatin injection, animals were housed separately in metabolic cages. 24-h urine samples were collected for estimation of creatinine clearance. Samples from the collected urine were centrifuged for $15 \mathrm{~min}$ at $604 \mathrm{~g}$ and then kept frozen until analyzed. Urinary micrototal protein (MTP) and creatinine were measured in these samples. On day 10 of the experiment, animals were anesthetized with ether and blood samples withdrawn from retro-orbital plexus. Sera were prepared by 
centrifugation of blood for $5 \mathrm{~min}$ at $1000 \mathrm{~g}$. Kidneys were isolated and washed with ice-cold isotonic saline $(0.9 \%)$. The right kidney of each animal was used for histopathology while the left kidney was homogenized in ice-cold $0.1 \mathrm{M}$ of phosphate buffer $(\mathrm{pH}$ 7.4) to obtain a $10 \% \mathrm{w} / \mathrm{v}$ kidney homogenates using a handheld homogenizer (Oncu et al. 2002). Kidney homogenates were centrifuged at 9,000g at $4^{\circ} \mathrm{C}$ using cooling centrifuge and the supernatant obtained were used for assessment of MDA, glutathione (GSH), SOD and cytokine levels.

\section{Biochemical measurements}

\section{Determination of serum creatinine, BUN, and urinary MTP levels:}

Creatinine, BUN in rat sera, and urinary MTP levels were measured using commercially available kits (Human Diagnostics Co., Egypt).

\section{Determination of urinary creatinine clearance:}

The amount of creatinine excreted in 24 hour -collected urine was used to estimate creatinine clearance (Kellen et al. 1994)

\section{Determination of renal MDA levels:}

MDA was estimated using the method described by Ohkawa et al. (1979). Briefly, $1.5 \mathrm{ml}$ of $20 \%$ acetic acid adjusted to $\mathrm{pH} 3.5$ using $\mathrm{NaOH}, 200 \mu \mathrm{L}$ of $8.1 \%$ sodium dodecyl sulfate and $1.5 \mathrm{ml}$ of $0.8 \%$ aqueous solution of thiobarbituric acid were added to $200 \mu \mathrm{L}$ of kidney homogenate. The reaction mixture was completed to $4 \mathrm{ml}$ then heated at $95^{\circ} \mathrm{C}$ for $60 \mathrm{~min}$. After cooling of the mixture, $1 \mathrm{ml}$ of distilled water was 
added to every sample then all samples were centrifuged. The organic layer was taken and the absorbance was measured at $532 \mathrm{~nm}$ by a spectrophotometer and compared with those obtained from MDA standards. MDA was expressed as nmol/g tissue.

\section{Determination of renal GSH level:}

The level of GSH in kidney homogenates was assayed colorimetrically using the method described earlier by Ellman (1959). An aliquot of the homogenate was mixed with 5\% metaphosphoric acid and the mixture was centrifuged at $2000 \mathrm{~g}$ for $5 \mathrm{~min}$. An aliquot of the supernatant was added to $1.9 \mathrm{ml}$ of $0.1 \mathrm{M}$ phosphate buffer $\mathrm{pH} 8.0$ and $20 \mu \mathrm{l}$ of $0.02 \mathrm{M} \mathrm{5,5-dithio-bis-(2-nitrobenzoic} \mathrm{acid)} \mathrm{in} 0.1 \mathrm{M}$ phosphate buffer $\mathrm{pH}$ 8.0. The absorbance of samples was read at $412 \mathrm{~nm}$ on a spectrophotometer. The concentration of GSH in each sample was calculated in reference to a GSH calibration curve derived from a serial dilutions of a $240 \mu \mathrm{M}$ of GSH stock solution that were handled in identical manner as the kidney homogenate samples. The result was reported as $\mu \mathrm{M} / \mathrm{g}$ tissue.

\section{Determination of renal SOD activity:}

SOD activity, as an indicator of endogenous antioxidant activity, were measured in duplicates by measuring the SOD-inhabitable autooxidation of pyrogallol using the method described by Marklund (1985). The reaction mixture (4.5 ml) was prepared by adding $0.2 \mathrm{mmol} / \mathrm{L}$ of pyrogallol, $1 \mathrm{mmol} / \mathrm{L}$ of diethylene triaminepenta-acetic acid, $50 \mathrm{mmol} / \mathrm{L}$ of tris-cacodylic acid buffer $(\mathrm{pH} 8.2)$ and $4 \mu \mathrm{g}$ of catalase. The reaction 
was done at $25^{\circ} \mathrm{C}$ and the absorbance was recorded at $420 \mathrm{~nm}$ using a spectophotometer. Fifty percent inhibition of pyrogallol autooxidation was considered as one unit of enzyme activity. Renal SOD activity was expressed as U/g tissue.

\section{Renal NF-кB activation:}

The transcription factor NF-kB activation was measured according to manufacturer's instructions using a commercially available ELISA kit (Trans-AM ${ }^{\mathrm{TM}}$ NF-kB p65 Transcription Factor Assay Kit, Active Motif, CA). Nuclear protein extract was obtained using Nuclear Extract Kit (Active Motif) according to manufacturer's instruction. Subsequently, $5 \mu \mathrm{g}$ nuclear protein extract from each sample was used to assay for NF- $\mathrm{kB}$ activation. Values were represented as OD $450 \mathrm{~nm}$.

\section{Assessment of IL-6 and TNF- $\alpha$}

For estimation of pro-inflammatory cytokines in kidney tissues, IL-6 and TNF- $\alpha$ were measured in the supernatant of kidney homogenates using IL-6 and TNF- $\alpha$ ELISA assay kits (Bender Med. Systems GmbH, Vienna, Austria). Tests procedures were carried out according to the supplied manufacturers' instructions. The concentrations of TNF- $\alpha$ and IL-6 in kidney tissues were expressed as pg/mg protein.

\section{Histopathology}

The renal tissues of all groups were immediately removed, fixed in $10 \%$ neutral buffered formalin, then dehydrated in ascending grades of alcohol, cleared in xyline and embedded in paraffin. Paraffin blocks were made and tissue sections ( $5 \mu \mathrm{m})$ were 
cut and stained with Hematoxylin-Eosin (H\&E) for general histological examination. The sections were scored by the percentage of tubules that displayed tubular necrosis, cast formation, and tubular dilation as previously described by Kim et al. (2012). $0=$ normal; $1=<10 \% ; 2=10-25 \% ; 3=26-50 \% ; 4=51-75 \%$; and $5=>75 \%$. Necrotic cell death was scored by assessing the percentage of tubules with increased eosinophilia, cytoplasmic vacuolization, or loss of architecture and nucleus.

For immunohistochemical staining (Guesdon et al. 1979); serial sections ( $3 \mu \mathrm{m})$ were deparaffinized, followed by endogenous peroxidase blocking with 3\% $\mathrm{H} 2 \mathrm{O} 2$ for 20 min. The slides were then incubated overnight at $4 \circ \mathrm{C}$ with rabbit polyclonal antibody directed against NF- КB p65 (dilution 1:100; Santa Cruz Biotechnology, Santa Cruz, CA, USA). Sections were then washed in PBS and incubated with biotinylated antimouse IgG (Sigma Chemicals Co., St Louis, MO,USA), followed by washing in PBS and then incubation with Avidin-Biotin-Peroxidase complex solution (Sigma Chemicals Co., St. Louis, MO, USA). The antibody bound to sections was visualized by treatment with $0.05 \%(w / v)$ 3,3'-diaminobenzidine tetrahydrochloride (Sigma Chemicals Co., St. Louis, MO, USA). The sections were stained by Mayer's Hematoxylin as a counter stain. Positive reaction appears as a brown color which is detected in the cytoplasm and nuclei. Positivity was considered only as nuclear immunostaining. Negative controls were obtained by incubation with a nonspecific IgG antibody at the same concentration as the primary antibody. Leica Qwin 500 
(Imaging System, Cambridge, UK) was used for counting NF-אB immunopositive cells that exhibit only nuclear reaction in immunostained sections. Five nonoverlapping sections from each paraffin block for each rat were taken (30 measurements for each group) and examined at high -power fields $(\times 400)($ Sung et al. 2008). Morphometric measurements were taken within frame area of $293.4288 \mu \mathrm{m} 2$. Morphometry was carried out at the Image Analysis Unit, Faculty of Medicine, Taibah University, Al Medinah Al-Munawarah, Saudi Arabia.

\section{Statistical analysis}

Data are expressed as means \pm standard error of the mean (SEM). A statistical analysis for parametric measures was performed using one-way analysis of the variance (ANOVA) followed by Tukey-Kramer multiple comparison test to estimate the difference between the various groups. Statistical analysis for non-parametric scoring data was carried out using a Kruskal-Walis test followed by Dunn for comparing all pairs. Statistical calculations were carried out using INSTAT-2 computer program (GraphPad Software Inc. V2.04, San Diego, CA, USA).

\section{Results:}

\section{Effect of TMZ on biochemical parameters in CSP-treated rats}

\section{Effect on kidney functions:}

CSP administration was associated with a significant increase in serum creatinine, BUN and MTP accompanied by a significant decrease in creatinine clearance when 
compared to the control group. Treatment with TMZ in CSP-injected rats caused a significant improvement in all measured kidney function parameters as compared to CSP- treated group (table 1).

\section{Effect on prooxidnats/antioxidant status:}

Acute CSP administration significantly increased renal MDA but significantly decreased renal GSH and SOD levels compared to vehicle treated rats. TMZ treatment significantly restored CSP-induced imbalance in oxidant/antioxidant status (table 2).

\section{Effect of TMZ on CSP-induced changes in renal histopathology (H\&E stains):}

Histopathological findings (figure 1; A \& B) of kidneys from control rats (vehicle and TMZ alone groups) showed intact histology, whereas kidneys from CSP-treated rats showed severe damage of the tubules with degeneration, necrosis, shedding of the tubular epithelium, vacuolation, infiltration of inflammatory cells and accumulation of casts in their lumina (figure 1; C1,C2 \& C3). Kidney tissue sections from TMZCSP treated rats showed a decrease in tubular necrosis, vacuolation, infiltration of inflammatory cells and accumulation of homogenous material in tubular lumen and all other pathological changes as compared to CSP group (figure 1; D1\&D2). Also, the score of histological damage in tubular epithelial cells of the cortex after CSP injection was significantly reduced upon treatment with TMZ (table 5). 


\section{Effect of TMZ on CSP-induced inflammation}

To evaluate whether TMZ can attenuate renal inflammation caused by CSP administration, the levels of proinflammatory cytokines TNF- $\alpha$ and IL-6 in kidney homogentaes were measured. As shown in table 3, TNF- $\alpha$ and IL-6 were significantly increased in kidneys from CSP only treated rats when compared to control rats. TMZ administration significantly reduced CSP-evoked increase in TNF- $\alpha$ and IL- 6 when compared to CSP treated rats. To further elucidate the mechanisms mediating the effects of TMZ on CSP- induced renal inflammation, assessment of the percentage of cells demonstrating nuclear staining for NF- $\mathrm{BB}$ and also the degree of DNA-binding activity of NF- $\kappa \mathrm{B}$ (p65) in nuclear fractions extracted from rat kidneys were done. Results from immunohistochemistry analysis of the kidney (figure 2) showed negative NF-אB immunoreaction in both control and TMZ groups (figure 2; A \& B), increased number of NF- $\mathrm{NB}$ positive cells with nuclear staining in CSP-treated group (figure 2; C) whereas TMZ-GSP group showed a marked decrease in the number of these positive cells (figure 2; D). Also, The DNA binding activity of NF- $\kappa \mathrm{B}$ (p65) was significantly higher in CSP only treated rats compared to control. TMZ administration before and along with CSP caused a significant decrease in the number of positive

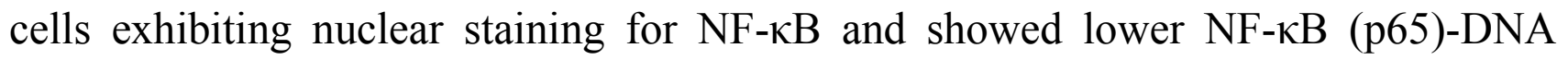
binding activity as compared to CSP - treated rats (table 4). 


\section{Discussion}

Nephrotoxicity is a serious side effect associated with CSP chemotherapy (Sastry and Kellie 2005). The present study demonstrated that TMZ treatment along with CSP could largely ameliorate CSP-induced nephrotoxicity in rats. TMZ treatment reduced CSP-induced renal oxidative stress, restored renal antioxidant activity and attenuated expression and activation of transcription factor NFK-B and the proinflammatory cytokines TNF- $\alpha$ and IL- 6 . These findings may indicate the molecular basis for the beneficial role of TMZ against CSP-induced nephrotoxicity. In agreement with previous studies (Badary et al. 2005; Kawai et al. 2006; Kumari and Setty 2012), i.p. injection of CSP caused histopathological changes of rat kidneys. The structural damage was associated with significant deterioration in kidney function as reflected by a significant elevation of serum creatinine and BUN associated with significant reduction of creatinine clearance and with proteinurea as compared to the control group.

The major site of renal injury caused by CSP is the S3 segment of the proximal tubule where it usually accumulates. The exposure of tubular cells to CSP activates complex signaling pathways mediating tubular cell injury and death. CSP may also induce injury in renal vasculature resulting in decreased blood flow and ischemic injury leading to a decline in glomerular filtration rate. Together, these events may end with 
the loss of renal function with manifestations of acute renal failure during CSPinduced nephrotoxicity (Pabla and Dong 2008).

The mechanisms underlying CSP-induced nephrotoxicity are multiple but are not fully understood. However, evidence of these mechanisms at molecular level is evolving and had been reviewed by many authors (Miller et al. 2010; Sancho-Martínez et al. 2012; Peres and da Cunha 2013). Mechanisms of CSP-induced nephrotoxicity involve an increase in renal oxidative stress, induction of renal tubular cell apoptosis and activation of key cytokines playing an important role in the inflammatory pathways (El-Naga 2014; Hagar et al. 2015). Kim et al. (2012) demonstrated that necrosis and inflammation are major determinants of CSP nephrotoxicity and that the inhibition of necrotic cell death and inflammation prevents CSP nephrotoxicity even when apoptosis persists. Their data are supported by the finding that the predominant lesion is acute necrosis in patients with CSP acute kidney injury (Yao et al. 2007). Early observations by Lieberthal et al. (1996) and Shino et al. (2003) have demonstrated that the apoptotic or necrotic cell death is dependent on the CSP concentration and duration of treatment. Apoptosis occurs upon low concentrations of CSP for a long time, whereas necrosis is observed at high concentrations of CSP for a short time. Many studies demonstrated that CSP can induce free radicals production and oxidative damage with lipid peroxidation in the kidney (Park et al. 2008; Sahu et al. 2011). CSP causes generation of highly reactive oxygen species such as superoxide 
and hydroxyl radicals which can attack and modify cellular components including DNA, lipids, and proteins to eventually cause cell death (Satoh et al. 2003).

In the current study, kidneys from CSP-treated group showed significantly higher levels of the lipid peroxidation marker; MDA and significantly lower levels of the antioxidant defense system GSH and SOD as compared with the control group. Treatment with TMZ restored prooxidants-antioxidant balance evident by a significant decrease in renal MDA level and increase in GSH level and SOD activity. Findings from previous studies support the hypothesis that $\mathrm{TMZ}$ exerts a renoprotective effect that could be related to its effect on oxidative stress and antioxidants systems. Satyanarayana and Chopra (2002) reported a similar ameliorative effect of TMZ on oxidative markers in gentamicin-induced nephrotoxicity. Also Kaur et al. (2003) proved the protective effect of $\mathrm{TMZ}$ in ROS-induced renal failure during ischemia/reperfusion injury in rats is due to its ability to increase antioxidant and oxygen free radical scavenger activity. However, the mechanism by which TMZ may shift the oxidative status in favor of more antioxidant effect is not fully clear.

In addition to the effect on oxidative status; TMZ cytoprotective effect in the kidney was suggested to be mediated by its role in optimizing energy metabolism of the mitochondria of renal tubular cells (Cristina et al. 2013).

Inflammation has been observed to be a part of CSP-induced nephrotoxicity. CSPinduced ROS production in renal tubular cells mediates activation of NF- $\mathrm{BB}$ leading 
to increased inducible nitric oxide synthase and pro-inflammatory cytokines, and adhesion molecules with infiltration of inflammatory cells kidney tubules (Sung et al. 2008; Mukhopadhyay et al. 2012; Sahu et al. 2014). CSP causes increased production of TNF- $\alpha$ in the kidney which is highly dependent upon ROS production and activation of p38 mitogen-activated protein kinases (Ramesh and Reeves 2005). In the kidney, the classic form of the transcription factor, NF- $\kappa \mathrm{B}$ is a heterodimer of a p65 (RelA) and p50 (c-Rel) subunits (Guijarro and Egido 2001). NF- $\kappa \mathrm{B}$ is normally sequestered in the cytoplasm by $\operatorname{IkB} \alpha$ subunit. When the complex is exposed to ROS, it breaks down allowing NF- $\mathrm{BB}$ to translocate into the nucleus stimulating the transcription of various inflammatory genes. Inhibition of NFא-B correlates with attenuation of CSP nephrotoxicity (Ramesh and Reeves 2004).

The current study revealed a significant increase in the number of renal cells with immunoreactivity of NFK-B in the nucleus and increased DNA binding activity of NF$\kappa \mathrm{B}$ (p65) (figure 2 and table 4). These changes were concomitant with significantly higher concentration of TNF- $\alpha$ and IL-6 in the kidneys of CSP administered rats. TMZ treatment effectively scavenged CSP-induced ROS and suppressed the CSPinduced pro-inflammatory cytokines (TNF- $\alpha$ and IL-6) release and attenuated the NF$\kappa \mathrm{B}$ activation. The ability of $\mathrm{TMZ}$ to reduce inflammation through decreasing proinflammatory cytokines was demonstrated in experimental cardiac remodeling (Zhou et al. 2012) and also with inflammation associated with pancreatitis (Tanoglu et 
al 2015). Sahu et al. (2015) reported that CSP-induces expression of iNOS, TNF- $\alpha$, IL-6 and activates redox-sensitive transcription factor NF- $\mathrm{B}$ with increased DNAbinding activity, I $\mathrm{B} \mathrm{B} \alpha$ phosphorylation and p65 nuclear translocation in mice kidneys. Several previous studies proved that TNF- $\alpha$ is a critical mediator in the inflammatory response contributing to tissue damage during CSP nephrotoxicity and demonstrated that kidney resident cells, rather than the infiltrating inflammatory cells, are the major source of TNF- $\alpha$ production during CSP nephrotoxicity (Ramesh and Reeves 2002; Zhang et al. 2007). Pharmacological inhibition or genetic deletion of TNF- $\alpha$, reduces CSP-induced epithelial cell necrosis and apoptosis, infiltration of leukocytes and renal dysfunction (Sung et al. 2008). IL-6 is a pro-inflammatory downstream mediator in TNF- $\alpha$ / NF- $\kappa \mathrm{B}$ signaling pathway and is increased in CSP-nephrotoxicity. Results of the present study documented increased IL-6 in CSP only group that was ameliorated by $\mathrm{TMZ}$ pretreatment.

In conclusion, the current study showed a clear protective effect of TMZ against CSPinduced acute kidney injury in rats. The mechanisms mediating such effect are related to TMZ ability to reduce oxidative stress in the kidney. It may also involve inhibition of NF- $\kappa \mathrm{B}$ activation and attenuation of subsequent pro-inflammatory mediators release in the kidney. However, further clinical studies are needed to further elucidate whether it could be used in the clinical setting as an adjunct candidate to CSP therapy. 


\section{Conflict of interest:}

There is no conflict of interest concerning this work

\section{Acknowledgement:}

The author acknowledges Dr. Heba M. Wagih, Medical Laboratories Technology Department, Faculty of Applied Medical Sciences, Taibah University, Saudi Arabia; Pathology Department, Faculty of Medicine, Suez Canal University, Egypt for providing assistance.

No fund.

\section{References:}

- Badary, O.A., Abdel-Maksoud, S., Ahmed, W.A., and Owieda, G.H. 2005. Naringenin attenuates cisplatin nephrotoxicity in rats. Life Sci. 76 (18): 2125-135. PMID: 15826879.

- Cristina de, L.C., Del Rosario, R.M., Carmen Rosa, A., and Ana Veronica, O. 2013. On the performance of trimetazidine and vitamin e as pharmacoprotection agents in cyclosporin a-induced toxicity. ISRN Pharmacol. 605640. doi: 10.1155/2013/605640. PMID: 23691353.

- Ellman, G.L. 1959. Tissue sulfhydryl groups. Arch. Biochem. Biophys. 82 (1): 707. PMID: 13650640. 
- El-Naga, R.N. 2014. Pre-treatment with cardamonin protects against cisplatininduced nephrotoxicity in rats: impact on NOX-1, inflammation and apoptosis. Toxicol. Appl. Pharmacol. 274 (1): 87-95.doi: 10.1016/j.taap.2013.10.031. PMID: 24211271.

- Guesdon, J.L., Ternynck, T., and Avrameas, S. 1979. The use of avidin biotin interaction in immunoenzymatic techniques. J. Histochem. Cytochem. 27 (8): 1131- 9. PMID: 90074.

- Guijarro, C., and Egido, J. 2001. Transcription factor-Kappa B (NF-Kappa B) and renal disease. Kidney int. 59 (2): 415-24. PMID: 11168923.

- Hagar, H., El Medany, A., Salam, R., El Medany, G., and Nayal, O.A. 2015. Betaine supplementation mitigates cisplatin-induced nephrotoxicity by abrogation of oxidative/nitrosative stress and suppression of inflammation and apoptosis in rats. Exp. Toxicol. Pathol. 67 (2): 133- 41. doi: 10.1016/j.etp.2014.11.001. PMID: 25488130.

- Hanigan, M.H., and Devarajan, P. 2003. Cisplatin nephrotoxicity: molecular mechanisms. Cancer Ther. 1: 47-61. PMID: 18185852.

- Kantor, P.F., Lucien, A., Kozak, R., and Lopaschuk, G.D. 2000. The antianginal drug trimetazidine shifts cardiac energy metabolism from fatty acid oxidation to glucose oxidation by inhibiting mitochondrial long-chain 3-ketoacyl coenzyme A thiolase. Circ. Res. 86 (5): 580-88. PMID: 10720420. 
- Kaur, H., Padi, S.S., and Chopra, K. 2003. Attenuation of renal ischemiareperfusion injuy by trimetazidine: evidence of an in vivo antioxidant effect. Methods Find. Exp. Clin. Pharmacol. 25 (10): 803-09. PMID: 14735228.

- Kawai, Y., Nakao, T., Kunimura, N., Kohda, Y., and Gemba, M. 2006. Relationship of intracellular calcium and oxygen radicals to Cisplatin-related renal cell injury. J. Pharmacol. Sci. 100 (1): 65-72. PMID: 16410676.

- Kellen, M., Aronson, S., Roizen, M.F., Barnard, J., and Thisted, R.A. 1994. Predictive and diagnostic tests of renal failure: a review. Anesth. Analg. 78 (1): 134-42. PMID: 8267149.

- Khan, M., Meduru, S., Mostafa, M., Khan, S., Hideg, K., and Kuppusamy, P. 2010. Trimetazidine, administered at the onset of reperfusion, ameliorates myocardial dysfunction and injury by activation of p38 mitogen-activated protein kinase and Akt signaling. J. Pharmacol. Exp. Ther. 333 (2): 421-29. doi: 10.1124/jpet.109.165175. PMID: 20167841.

- Kim, J., Long, K.E., Tang, K., and Padanilam, B.J. 2012. Poly (ADP- ribose) polymerase 1 activation is required for cisplatin nephrotoxicity. Kidney Int. 82 (2): 193-203. doi: 10.1038/ki.2012.64. PMID: 22437413.

- Kumari, K.K., and Setty, O.H. 2012. Protective effect of Phyllanthusfraternus against mitochondrial dysfunction induced by co-administration of cisplatin and 
cyclophosphamide .J. Bioenerg. Biomembr. 44 (1):179- 88. doi: 10.1007/s10863012-9423-9426. PMID: 22362056.

- Lieberthal, W., Triaca, V., and Levine, J. 1996. Mechanisms of death induced by cisplatin in proximal tubular epithelial cells: apoptosis vs. necrosis. Am. J. Physiol. 270 (4 Pt 2): F700-08. PMID: 8967349.

- Marklund, S.L. 1985. Superoxide dismutase isoenzymes in tissues and plasma from New Zealand black mice, nude mice and normal BALB/c mice. Mutat. Res. 148 (1-2): 129- 34. PMID: 3969077.

- Miller, R.P., Tadagavadi, R.K., Ramesh, G., and Reeves, W.B. 2010. Mechanisms of Cisplatin nephrotoxicity. Toxins (Basel), 2 (11): 2490-518. doi: 10.3390/toxins 2112490. PMID: 22069563.

- Mukhopadhyay, $\quad$ P., Horváth, $\quad$ B., Zsengellér, $\quad$ Z., Zielonka, J., Tanchian, G., Holovac, E., et al. 2012. Mitochondrial-targeted antioxidants represent a promising approach for prevention of cisplatin-induced nephropathy. Free Radic. Biol. Med. 52 (2):497-506. doi: 10.1016/j.freeradbiomed.2011.11.001. PMID: 22120494.

- Oh, G.S., Kim, H.J., Shen, A., Lee, S.B., Khadka, D., Pandit, A., et al. 2014. Cisplatin-induced kidney dysfunction and perspectives on improving treatment strategies. Electrolyte Blood Press. 12 (2): 55-65. doi: 10.5049/EBP.2014.12.2.55. PMID: 25606044 
- Ohkawa, H., Ohishi, N., and Yagi, K. 1979. Assay for lipid peroxides in animal tissues by thiobarbituric acid reaction. Anal. Biochem. 95 (2):351- 58. PMID: 36810.

- Oncu, M., Gultekin, F., Karao“z, E., Altuntas, I., and Delibas, N. 2002. Nephrotoxicity in rats induced by chlorpryfos-ethyl and ameliorating effects of antioxidants. Hum. Exp. Toxicol. 21 (4): 223-30. PMID: 12099624.

- Pabla, N., and Dong, Z. 2008. Cisplatin nephrotoxicity: mechanisms and renoprotective strategies. Kidney Int. 73 (9): 994-1007.doi: 10.1038/sj.ki.5002786. PMID: 18272962.

- Park, H.M., Cho, J.M., Lee, H.R., Shim, G.S., and Kwak, M.K. 2008. Renal protection by $3 \mathrm{H}-1,2$-dithiole-3-thione against cisplatin through the Nrf2antioxidant pathway. Biochem. Pharmacol. 76 (5): 597-607. doi: 10.1016/j.bcp.2008.06.021. PMID: 18656455.

- Park, K.H., Park, W.J., Kim, M.K., Park, D.W., Park, J.H., Kim, H.S., et al. 2010. Effects of trimetazidine on endothelial dysfunction after sheath injury of radial artery. Am. J. Cardiol. 105 (12): 1723-27. doi: 10.1016/j.amjcard.2010.01.351. PMID: 20538121.

- Peres, L.A., and da Cunha, A.D.Jr. 2013. Acute nephrotoxicity of cisplatin: molecular mechanisms. J. Bras. Nefrol. 35 (4): 332-40. doi: 10.5935/01012800.20130052. PMID: 24402113. 
- Ramesh, G., and Reeves, W.B. 2002. TNF-alpha mediates chemokine and cytokine expression and renal injury in cisplatin nephrotoxicity. J. Clin. Invest. 110 (6): 835-42. PMID: 12235115.

- Ramesh, G., and Reeves, W.B. 2004. Salicylate reduces cisplatin nephrotoxicity by inhibition of tumor necrosis factor-alpha. Kidney Int. 65 (2): 490-9. PMID: 14717919.

- Ramesh, G., and Reeves, W.B. 2005. p38 MAP kinase inhibition ameliorates cisplatin nephrotoxicity in mice. Am. J. physiol. 289 (1): F166-74. PMID: 15701814.

- Sahu, B.D., Kalvala, A.K., Koneru, M., Kumar, J.M., Kuncha, M., Rachamalla, S., et al. 2014. Ameliorative Effect of Fisetin on Cisplatin-Induced Nephrotoxicity in Rats via Modulation of NF-кB Activation and Antioxidant Defence. PloS One, 9 (9): e105070.doi: 10.1371/journal.pone.0105070. PMID: 25184746.

- Sahu, B.D., Kumar, J.M., and Sistla, R. 2015. Baicalein, a Bioflavonoid, Prevents Cisplatin-Induced Acute Kidney Injury by Up-Regulating Antioxidant Defenses and Down-Regulating the MAPKs and NF-кB Pathways. PLoS One, 10 (7):e0134139. doi: 10.1371/journal.pone.0134139. PMID: 26222683.

- Sahu, B.D., Rentam, K.K., Putcha, U.K., Kuncha, M., Vegi, G.M., and Sistla, R. 2011. Carnosic acid attenuates renal injury in an experimental model of rat 
cisplatin-induced nephrotoxicity. Food Chem. Toxicol. 49 (12): 3090-97, doi: 10.1016/j.fct.2011.08.018. PMID: 21930180.

- Sancho-Martínez, S.M., Prieto-García, L., Prieto, M., López-Novoa, J.M., and López-Hernández, F.J. 2012. Subcellular targets of cisplatin cytotoxicity: an integrated view. Pharmacol. Ther. 136 (1):35-55.doi: 10.1016/j.pharmthera.2012.07.003. PMID: 22796517.

- Sastry, J., and Kellie, S.J. 2005. Severe neurotoxicity, ototoxicity and nephrotoxicity following high-dose cisplatin and amifostine. Pediatr. Hematol. Oncol. 22 (5): 441-5. PMID: 16020136.

- Satoh, M., Kashihara, N., Fujimoto, S., Horike, H., Tokura, T., Namikoshi, T., et al. 2003. A novel free radical scavenger, edaravone, protects against cisplatininduced acute renal damage in vitro and in vivo. J. Pharmacol. Exp. Ther. 305 (3): 1183-90. PMID: 12649298.

- Satyanarayana, P.S., and Chopra, K. 2002. Oxidative stress-mediated renal dysfunction by cyclosporine A in rats: attenuation by trimetazidine. Ren. Fail. 24 (3): 259-74. PMID: 12166693.

- Sellier, P., and Broustet, J.P. 2003. Assessment of anti-ischemic and antianginal effect at trough plasma concentration and safety of trimetazidine MR $35 \mathrm{mg}$ in patients with stable angina pectoris. Am. J. Cardiovasc. Drugs, 3 (5): 361-9. PMID: 14728070. 
- Shino, Y., Itoh, Y., Kubota, T., Yano, T., Sendo, T., and Oishi, R. 2003. Role of poly (ADP-ribose) polymerase in cisplatin-induced injury in LLC-PK1 cells. Free Radic. Biol. Med. 35 (8): 966-77. PMID: 14556861.

- $\quad$ Sung, M.J., Kim, D.H., Jung, Y.J., Kang, K.P., Lee, A.S., Lee, S., et al. 2008. Genistein protects the kidney from cisplatin-induced injury. Kidney Int. 74 (12):1538-47. doi: 10.1038/ki.2008.409. PMID: 18716605.

- Tanoglu, A., Yazgan, Y., Kaplan, M., Berber, U., Kara, M., Demırel, D., et al. 2015. Trimetazidine significantly reduces cerulein-induced pancreatic apoptosis. Clin. Res. Hepatol. Gastroenterol. 39 (1): 145-50. doi: 10.1016/j.clinre.2014.06.003. PMID: 25001186.

- Winston, J.A., and Safirstein, R. 1985. Reduced renal blood flow in early cisplatin-induced acute renal failure in the rat. Am. J. Physiol. 249 (4 pt 2): F4906. PMID: 4051003.

- Yao, X., Panichpisal, K., Kurtzman, N., and Nugent, K. 2007. Cisplatin nephrotoxicity: a review. Am. J. Med. Sci. 334 (2): 115-24. PMID: 17700201.

- Zhang, B., Ramesh, G., Norbury, C.C., and Reeves, W.B. 2007. Cisplatin-induced nephrotoxicity is mediated by tumor necrosis factor- $\alpha$ produced by renal parenchymal cells. Kidney Int. 72 (1): 37-44. PMID: 17396112.

- Zhou, X., Li, C., Xu, W., and Chen, J. 2012. Trimetazidine Protects against Smoking-Induced Left Ventricular Remodeling via Attenuating Oxidative Stress, 
Apoptosis, and Inflammation. PLoS One, 7 (7): e40424. doi: 10.1371/journal.pone.0040424. PMID: 22792312. 
Table 1: Effect of trimetazidine (TMZ) administration $(20 \mathrm{mg} / \mathrm{kg})$ with or without cisplatin (CSP) $(6 \mathrm{mg} / \mathrm{kg})$ on kidney function parameters in rats

\begin{tabular}{ccccc}
\hline Group & $\begin{array}{c}\text { Serum creatinine } \\
(\mathbf{m g} / \mathbf{d l})\end{array}$ & $\begin{array}{c}\text { Blood urea nitrogen } \\
(\mathbf{m m o l} / \mathbf{L})\end{array}$ & $\begin{array}{c}\text { Urinary creatinine } \\
\text { clearance }(\mathbf{m l} / \mathbf{m i n})\end{array}$ & $\begin{array}{c}\text { Micrototal } \\
\text { proetinurea } \\
(\mathbf{m g} / \mathbf{d a y})\end{array}$ \\
\hline Control & $0.58 \pm 0.03$ & $21.14 \pm 1.61$ & $0.27 \pm 0.015$ & $5.00 \pm 0.35$ \\
TMZ & $0.56 \pm 0.05^{\#}$ & $21.7 \pm 2.18^{\#}$ & $0.26 \pm 0.013^{\#}$ & $4.92 \pm 0.17^{\#}$ \\
CSP & $8.86 \pm 0.56^{*}$ & $137.00 \pm 5.71^{*}$ & $0.09 \pm 0.04^{*}$ & $14.57 \pm 0.59^{*}$ \\
CSP/TMZ & $2.2 \pm 0.17^{* \#}$ & $53.2 \pm 6.9^{* \#}$ & $0.19 \pm 0.018^{\#}$ & $8.13 \pm 0.50^{* \#}$ \\
\hline
\end{tabular}

Data are expressed as mean $\pm \mathrm{SEM}, n=6$

* \# significantly different from control and cisplatin treated groups, respectively using one-way ANOVA followed by Tukey-Kramer multiple comparisons test $(P<0.05)$ 
Table 2: Effect of trimetazidine(TMZ) administration $(20 \mathrm{mg} / \mathrm{kg})$ with or without cisplatin (CSP) $(6 \mathrm{mg} / \mathrm{kg})$ on kidney oxidant/ antioxidants status in rats

\begin{tabular}{|l|c|c|c|}
\hline \hline Group & MDA (nmol/g tissue) & GSH $(\boldsymbol{\mu m o l} / \mathrm{g}$ tissue) & SOD (U/g tissue) \\
\hline \hline Control & $57.54 \pm 2.65$ & $7.81 \pm 0.42$ & $39.16 \pm 1.10$ \\
CSP & $58.38 \pm 2.72^{\#}$ & $7.94 \pm 0.45^{\#}$ & $42.23 \pm 2.27^{\#}$ \\
CSP/TMZ & $150.65 \pm 8.53^{*}$ & $3.78 \pm 0.16^{*}$ & $20.25 \pm 0.98^{*}$ \\
\hline \hline
\end{tabular}

MDA; malondialdehyde, GHS; reduced glutathione, SOD; superoxide dismutase

Data are expressed as mean $\pm \mathrm{SEM}, n=6$

* \# significantly different from control and cisplatin treated groups, respectively using one-way ANOVA followed by Tukey-Kramer multiple comparisons test $(P<0.05)$ 
Table (3): Effect of trimetazidine (TMZ) administration $(20 \mathrm{mg} / \mathrm{kg})$ with or without cisplatin (CSP) (6 mg/kg) on renal IL-6 and TNF- $\alpha$ :

\begin{tabular}{|l|c|c|}
\hline \hline & IL-6 (pg/mg protein) & TNF- $\alpha$ (pg/mg protein) \\
\hline \hline Control & $15.45 \pm 1.57$ & $10.57 \pm 0.99$ \\
\hline TMZ & $12.97 \pm 0.16 \#$ & $9.27 \pm 0.41 \#$ \\
\hline CSP & $65.57 \pm 5.77 *$ & $44.97 \pm 3.65 *$ \\
\hline CSP-TMZ & $23.11 \pm 2.42 \#$ & $15.50 \pm 1.56 \#$ \\
\hline \hline
\end{tabular}

IL-6; Interleukin-6, TNF- $\alpha$; Tumor necrosis factor-alpha

Values are represented as mean \pm S.E.M, $n=6$.

*\# Statistically significant as compared to the control and CSP-treated groups using one-way ANOVA test followed by Tukey-Kramer multiple comparison test $(P<0.05)$ 
Table 4: Effect of trimetazidine (TMZ) administration $(20 \mathrm{mg} / \mathrm{kg})$ with or without cisplatin (CSP) $(6 \mathrm{mg} / \mathrm{kg})$ on renal DNA-binding activity of NF-kB and number of positive cells with nuclear staining for NF-kB (p65) in rats

\begin{tabular}{|c|c|c|}
\hline & $\mathrm{NF}-\kappa \mathrm{B}$ activation (OD $450 \mathrm{~nm}$ ) & $\begin{array}{c}\text { Number of NF-kB positive } \\
\text { cells in nucleus }\end{array}$ \\
\hline Control & $0.75 \pm 0.05$ & $0.0 \pm 0.00$ \\
\hline TMZ & $0.85 \pm 0.07 \#$ & $0.0 \pm 0.00$ \\
\hline CSP & $3.21 \pm 0.33 *$ & $26.9 \pm 1.40 *$ \\
\hline CSP-TMZ & $0.99 \pm 0.12 \#$ & $9.0 \pm 0.43 \#^{*}$ \\
\hline
\end{tabular}

$\mathrm{NF}-\kappa \mathrm{B}$; nuclear factor kappa B

Values are represented as mean \pm S.E.M, $n=6$.

*\# Statistically significant as compared to the control and CSP-treated groups using one-way ANOVA test followed by Tukey-Kramer multiple comparison test $(P<0.05)$ 
Table 5: Effect of trimetazidine (TMZ) administration $(20 \mathrm{mg} / \mathrm{kg})$ with or without cisplatin $(\mathrm{CSP})(6 \mathrm{mg} / \mathrm{kg})$ on renal cortex score in rats

\begin{tabular}{|c|c|}
\hline \hline & Score intensity \\
\hline \hline Control & $0.0 \pm 0.00$ \\
\hline TMZ & $0.0 \pm 0.00$ \\
CSP & $4.4 \pm 0.40 *$ \\
\hline CSP-TMZ & $1.2 \pm 0.37 * \#$ \\
\hline \hline
\end{tabular}

Values are represented as mean \pm S.E.M, $n=6$.

*\# Statistically significant as compared to the control and CSP-treated groups using Kruskal-Walis test followed by Dunn for multiple comparison test $(P<0.05)$ 


\section{Figure Legend:}

Figure (1): A photomicrograph of sections in the renal cortex A): Control group, shows normal architecture of renal cortex with renal corpuscle (RC), glomerulus $(\mathrm{G})$, urinary space (arrow) and the parietal layer of bowman's capsule (arrow head) . Proximal convoluted tubules (PCT) are lined with high cubical cells with basal rounded nuclei and distal convoluted tubules (DCT) are lined with cubical epithelium with rounded central nuclei. The cells of both tubules have acidophilic cytoplasm and surrounded with intact basement membrane. B): TMZ group appears like control group showing also normal architecture of renal cortex with renal corpuscle (RC) ,glomerulus(G),intact parietal layer of bowman's capsule (arrow head) and urinary space (arrow).Proximal (PCT) and distal convoluted tubules (DCT) are surrounded with intact basement membrane. C1): CSP group shows disturbed architecture of renal cortex with shrinkage of renal corpuscle (RC), disruption of PCT and DCT and marked interstitial hemorrhage (stars). C2): CSP group with peritubular capillary congestion(star), inflammatory infiltrate(arrows) and tubular damage in the form of cell necrosis and loss(curved arrow), cell vacuolation and pyknosis (arrow head).C3):CSP group shows inflammatory infiltrate which is formed of neutrophils (thin arrow), plasma cells(thick arrow), monocytes(arrow head) and lymphocytes (curved arrow). Hyaline casts (star) is also observed in the lumens of renal tubules. D1): TMZ-CSP group with nearly preserved architecture of the renal cortex that shows apparently normal shaped renal corpuscle (RC), proximal (PCT) and distal convoluted tubules (DCT). D2): TMZ-CSP group shows nearly normal renal corpuscle (RC) with minimal glomerular congestion $(\mathrm{G})$ and normal capsular space (arrow), in addition to decrease of peritubular capillary congestion(curved arrow). PCT and DCT show normal appearance and intact cell lining like control group. (H\&E stain; A, B, C2 \& D2X400; C1\&D1X200; C3 X1000)

Figure (2): A photomicrographs of Anti $-\mathrm{NF}-\kappa \mathrm{B}$ (p65) immunostained sections of renal cortex of different rat groups; A) Control group and B) TMZ ,Both show negative NF- $\mathrm{\kappa B}$ immunoreaction in the renal corpuscle (RC), proximal (PCT) and distal convoluted (DCT) cells. C) CSP group show strong anti -NF- $\kappa B$ immunopositive reaction detected in the cytoplasm of nearly all cells and in the nuclei of many cells. Numerous NF- $\kappa \mathrm{B}$ positive cells (curved arrow) in the renal glomerulus (G) and many lining cells (arrows) of PCT\&DCT are observed. D) TMZ-CSP group 
show absence of the reaction in the cells of the glomerulus (G) like control group. Very few NF- $\kappa$ B positive cells (arrows) that exhibit nuclear reaction were seen in the wall of PCT \& DCT.

(Anti -NF- $\kappa$ B immunostain; A, B, C \& DX400). 


\section{Figure 1}

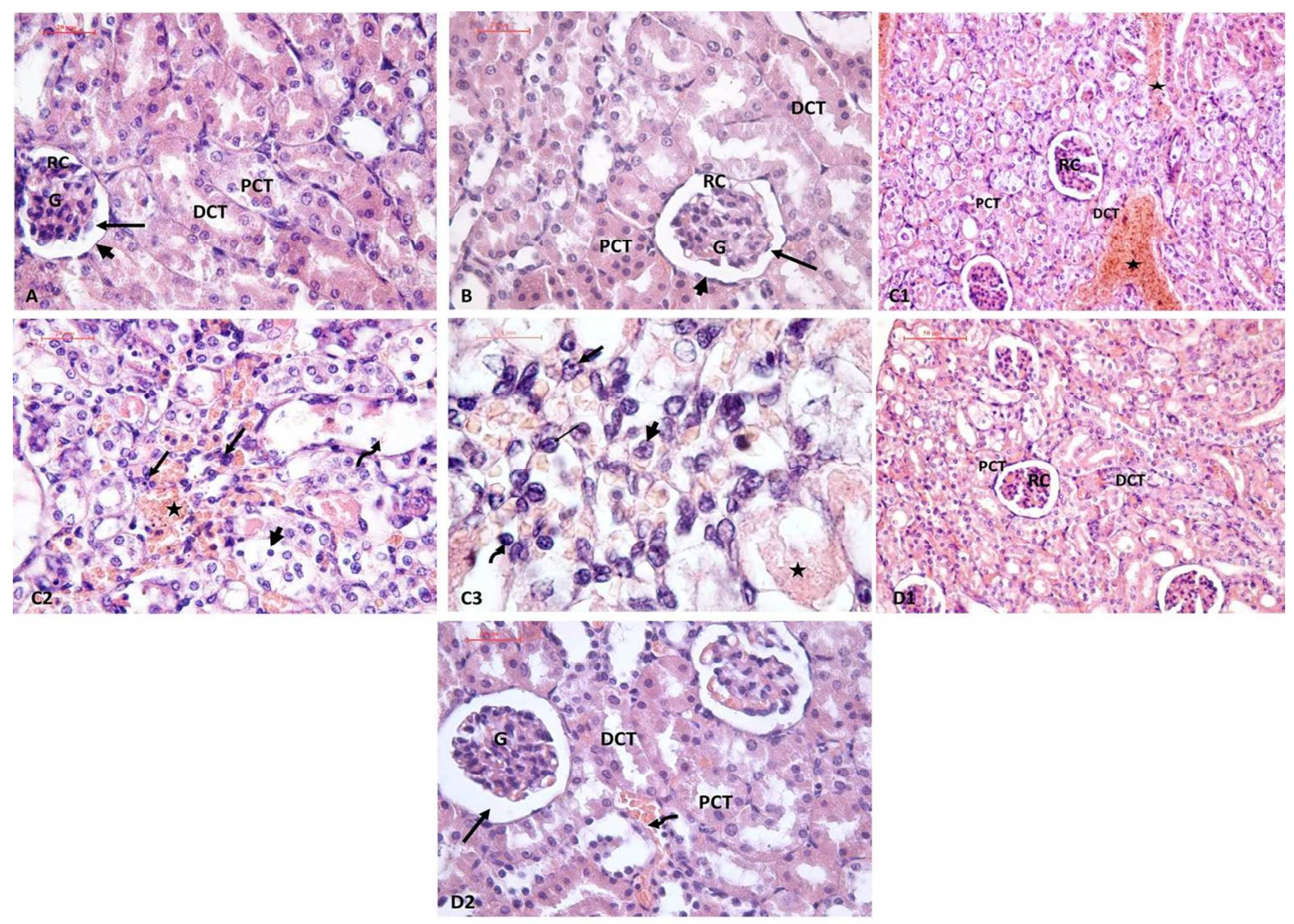


Figure 2
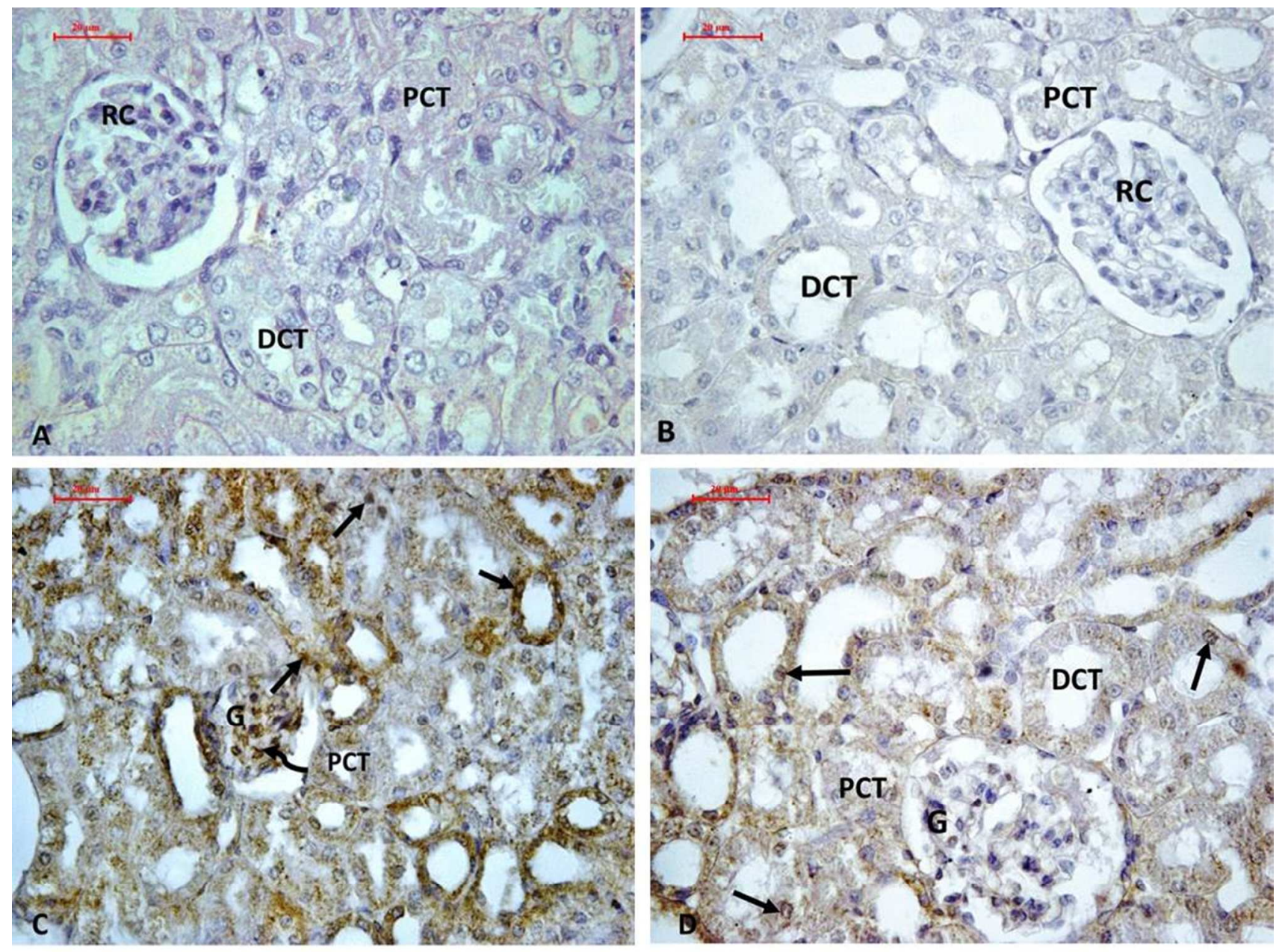